\title{
Terorisme di Suriah dan Implementasi Arms Trade Treaty
}

\author{
Dina Yulianti \\ Program Studi Hubungan Internasional Universitas Padjadjaran \\ dinay3007@gmail.com \\ R. Widya Setiabudi Sumadinata \\ Program Studi Hubungan Internasional Universitas Padjadjaran \\ wsetiabudi@yahoo.com
}

\section{ABSTRACT}

The Syrian war that started in 2012 involves the global distribution of weapons to armed militias or non-state actors (NSAs) with enormous capital value. Meanwhile, the Arms Trade Treaty (ATT) entered into force on December 24, 2014. It restricts the weapons-producing countries to export weapons to NSAs known to commit genocide and direct attacks on civilians. In this article the authors will answer two main questions, firstly, how is the NSA profile in the Syrian conflict and who are the sources of their armory; and secondly, how is the impact of ATT implementation on weapons proliferation. The method used in this research is qualitative text analysis, i.e. reviewing the research documents that have been done before, the documents of ATT, and mass media coverages. The finding of this research is that ATT is not effective in preventing supply of weaponry into the hands of the NSA and it caused the continuing war of Syria.

Keywords: Arms Trade Treaty, non-state actor, Syria, terrorism

\section{ABSTRAK}

Perang Suriah yang telah berlangsung sejak tahun 2012 melibatkan distribusi senjata global kepada milisi-milisi bersenjata atau non-state actor (NSA) dengan 
nilai kapital yang sangat besar. Sementara itu, sejak 24 Desember 2014 Arms Trade Treaty (ATT) telah diberlakukan yang berisi larangan bagi negara-negara produsen senjata untuk mengekspor senjata kepada NSA yang diketahui melakukan genosida dan serangan langsung terhadap warga sipil. Dalam artikel ini penulis akan menjawab dua pertanyaan utama, pertama bagaimana profil NSA dalam konflik Suriah dan darimana sumber suplai persenjataan mereka; serta kedua, bagaimana dampak implementasi ATT terhadap proliferasi senjata. Metode yang digunakan dalam penelitian ini adalah analisis teks kualitatif, yaitu menelaah dokumen-dokumen penelitian yang telah dilakukan sebelumnya, dokumen ATT, dan pemberitaan media massa. Temuan penelitian ini adalah bahwa ATT belum efektif dalam mencegah jatuhnya persenjataan ke tangan NSA sehingga perang di Suriah masih terus berlangsung.

Kata kunci: Arms Trade Treaty, non-state actor, Suriah, terorisme

\section{Pendahuluan}

Perang Suriah yang telah berlangsung sejak tahun 2012 merupakan sebuah arena perdagangan senjata global yang memunculkan ancaman besar bagi keamanan manusia di kawasan Timur Tengah dan dunia pada umumnya. Berbagai jenis senjata peledak telah digunakan selama konflik ini, di antaranya peluru artileri, rudal, hulu ledak roket, mortir, bom pesawat, granat, dan perangkat peledak improvisasi (improvised explosive devices). Karakter persenjataan tersebut adalah efek ledaknya yang luas sehingga jika digunakan dalam sebuah kawasan padat penduduk akan merenggut korban secara acak dan sebagian besar adalah warga sipil.

Menurut laporan dari Balkan Investigating Reporting Network (BIRN), selama 2012-2016, delapan negara Eropa timur, yaitu Bosnia, Bulgaria, Croatia, Ceko, Montenegro, Slovakia, Serbia, dan Romania telah melakukan penjualan senjata sebesar 1,2 miliar Euro kepada negara-negara Timur Tengah (Arab Saudi, Yordania, UAE, dan Turki). Senapan serbu seperti AK-47, mortir, peluncur roket, tank anti senjata, dan senapan mesin berat telah dikirimkan dari negara-negara Balkan tersebut menuju semenanjung Arab dan negara-negara yang berbatasan dengan Suriah (Marzouk, et al. 2016).

Dalam penelitian tersebut juga ditemukan bahwa senjata-senjata itu digunakan oleh kelompok-kelompok milisi bersenjata yang termasuk dalam kategori Non-State Actor (NSA). Jatuhnya senjata ke tangan NSA sangat berkontribusi terhadap eskalasi 
konflik di Suriah, maupun konflik-konflik lain di seluruh dunia. Mayoritas konflik di dunia pada abad ke-21 adalah konflik kekerasan yang terjadi di dalam negara dengan pelaku NSA, yang umumnya menggunakan senjata ringan (small arms and light weapon). Sejak tahun 2000 jumlah kematian akibat terorisme yang dilakukan NSA telah meningkat drastis, terutama di delapan negara, yaitu Afghanistan, Mesir, Irak, Nigeria, Pakistan, Somalia, Suriah, dan Yaman. Akibatnya saat ini lebih dari sepertiga populasi dunia berada di kawasan-kawasan berbahaya; kawasan dimana kemiskinan merajalela dan menjadi penyumbang $98 \%$ populasi pengungsi di dunia (Gillis, 2017: 2-3).

Fenomena ini memunculkan desakan dari komunitas internasional agar negaranegara menaati Perjanjian Perdagangan Senjata (Arms Trade Treaty-ATT), yang mengatur perdagangan senjata internasional, mulai dari persenjataan ringan, hingga tank dan pesawat tempur, yang mulai diberlakukan pada 24 Desember 2014. ATT melarang negara-negara produsen senjata untuk mengekspor persenjataan mereka kepada pihak-pihak yang diketahui melakukan genosida, kejahatan kemanusiaan, pelanggaran Konvensi Jenewa 1949, serangan langsung terhadap warga sipil dan objek sipil, dan kejahatan perang lainnya yang didefinisikan oleh perjanjian internasional.

Dalam artikel ini penulis akan berusaha menjawab dua pertanyaan utama, pertama bagaimana profil NSA dalam konflik Suriah dan sumber suplai persenjataan mereka; serta kedua, bagaimana dampak implementasi ATT terhadap proliferasi senjata di pihak NSA. Metode yang digunakan dalam penelitian ini adalah analisis teks kualitatif, yaitu menelaah dokumen-dokumen penelitian yang telah dilakukan sebelumnya, dokumen ATT, dan pemberitaan media massa.

\section{Latar Belakang Konflik Suriah}

Konflik Suriah diawali pada Februari 2011 ketika muncul aksi-aksi demonstrasi massa yang menuntut demokratisasi dan reformasi pemerintahan yang selama lebih dari 30 tahun dikuasai oleh keluarga Assad. Mendiang Hafez Assad menjadi Presiden Suriah pada periode 1971-2000. Pemilu yang dilakukan pasca kematian Hafez Assad mengantarkan Bashar Assad (anak Hafez Assad) ke tampuk pemerintahan. Saat itu, Assad menjadi satu-satunya kandidat sehingga peserta pemilu hanya diminta memilih setuju atau tidak (Kifner, 2000).

Pergolakan di Suriah terjadi seiring dengan terjadinya gelombang demonstrasi massa di berbagai negara Timur Tengah pada tahun 2010-2011, mulai dari Tunisia, 
Libya, Mesir, Yaman, dan beberapa negara monarkhi Arab, di antaranya Bahrain. Penyebab terjadinya aksi-aksi demonstrasi ini umumnya sama, yaitu kemarahan dan frustasi terhadap sistem pemerintahan yang mereka anggap otoriter dan korup; sehingga tuntutan para demonstran pun umumnya sama, yaitu kebebasan, kesetaraan ekonomi, dan demokratisasi (Maoz, 2014).

Hasil dari aksi-aksi demonstrasi tersebut berbeda-beda di setiap negara. Tunisia relatif berhasil mendirikan pemerintahan baru yang lebih demokratis, sementara kini Mesir justru kembali ke pemerintahan otoriter di tangan militer. Di Libya, milisi yang berafiliasi dengan Al Qaida melakukan serangan bersenjata terhadap rezim Qaddafi dan dibalas dengan represi sehingga memunculkan konflik bersenjata. NATO kemudian melibatkan diri ke dalam konflik ini berdasarkan Resolusi Dewan Keamanan PBB no. 1973 yang memerintahkan negara-negara anggota Dewan Keamanan agar mengambil segala langkah yang diperlukan untuk melindungi rakyat sipil (to take all necessary measures to protect civilians under threat of attack in the country) (UN, 2011). Setelah NATO melakukan operasi militer selama delapan bulan (19 Maret 2011 hingga 31 Oktober 2011), Qaddafi terguling dan pemerintahan baru terbentuk. Namun hingga kini, pemerintah pasca Qaddafi tidak berhasil menciptakan stabilitas di Libya. Negara yang semula merupakan negara termakmur dan memiliki cadangan minyak terbesar di benua Afrika itu kini dilanda perang saudara dan perang melawan ISIS (Human Rights Watch, 2018).

Sementara itu, tuntutan demokratisasi dan reformasi di Suriah kini berubah menjadi perang asimetris antara milisi-milisi bersenjata yang sebagian besarnya berafiliasi dengan AI Qaida serta ISIS melawan tentara nasional Suriah. Dengan kata lain, peperangan yang terjadi adalah antara NSA melawan aktor negara. NSA umumnya mengklaim sedang melakukan perang suci (jihad) sehingga mereka sering disebut sebagai 'jihadis' dan menyatakan diri sedang berupaya mendirikan pemerintahan Islam (khilafah) di Suriah.

Perubahan arah gerakan massa, dari tuntutan demokratisasi kepada ambisi untuk mendirikan khilafah dimulai sejak kelompok jihad terkuat saat itu, Jabhah Al Nusrah, bersama sejumlah kelompok jihadis lainnya pada 20 November 2012 mendeklarasikan Brigade Koalisi Pendukung Khilafah. Al Nusrah telah beroperasi di Suriah sejak Agustus 2011 setelah Presiden Assad memenuhi tuntutan para demonstran untuk melepaskan aktivis-aktivis Islam yang berjejaring dengan Al Qaida dari penjara pada periode Mei-Juni 2011. Aksi bom bunuh diri pertama kali dilakukan Al Nusrah di Damaskus pada 23 Desember 2011 yang menewaskan 40 orang. Al Nusrah mengaku bertanggung jawab atas aksi itu pada 23 Januari 2012. 
Sejak itu pula, kelompok-kelompok jihad lainnya bermunculan, antara lain Ahrar alSham, Liwa al-Islam, dan Suqor al-Sham, yang didirikan oleh mantan tahanan politik dari penjara Saidnaya (Lister, 2014).

Milisi-milisi bersenjata di Suriah melakukan aksi-aksi terorisme sejak awal konflik, antara lain, bom bunuh diri, meledakkan bom di pusat-pusat keramaian, serta menembakkan rudal ke wilayah padat penduduk. Surat Sekjen PBB kepada Dewan Keamanan pada 25 Mei 2012 pertama kali melaporkan adanya aksi-aksi terorisme tersebut. Kemudian pada 11 Desember 2012 pemerintah AS menyatakan bahwa Jabhah Al Nusrah adalah nama lain dari Al Qaida Irak dan memasukkannya dalam daftar organisasi teroris internasional. Menurut laporan AS, sejak November 2011, Al Nusrah telah mengaku bertanggung jawab atas 600 serangan, termasuk lebih dari 40 serangan bunuh diri dan peledakan dengan bom rakitan di kota-kota Damaskus, Aleppo, Hamah, Dara, Homs, Idlib, dan Deir ez-Zour (Sulaeman, 2013).

Hingga pertengahan 2013, minimalnya ada 1000 kelompok jihad yang terbentuk dan semuanya bergantung kepada dukungan dana dan senjata dari luar negeri. Kelompok-kelompok ini juga merekrut sekitar 15.000 petempur asing yang berdatangan dari minimalnya 90 negara. Dengan demikian, konflik Suriah adalah konflik yang terinternasionalisasi dimana kelompok-kelompok oposisi membangun kekuatan diplomasi dari negara di luar Suriah (Turki) dan membentuk milisi-milisi tempur dengan petempur berasal dari luar negeri dan dukungan suplai senjata dari negara-negara asing. Dua kelompok jihad terbesar di Suriah adalah Islamic State of Iraq and Syria (ISIS) dan Jabhah AI Nusrah (Lister, 2014).

\section{Islamic State of Iraq and Syria (ISIS)}

ISIS telah berdiri sejak 1999 dengan sejumlah nama lain, seperti Jund AI Syam atau Jamaah Al Tawhid wa Al Jihad, di bawah kepemimpinan Abu Musab Al Zarqawi. Kelompok ini awalnya beranggotakan orang-orang Yordania dan bergerak di Kandahar dan Herat, Afghanistan. Mulai April 2010, ISIS dipimpin oleh Abu Bakr Al Baghdadi dan pada 29 Juni 2014 ia mendeklarasikan berdirinya Khilafah Islam (Islamic State).

Di tangan Baghdadi, ISIS berkembang menjadi organisasi teroris yang besar dengan 25.000 petempur di Suriah dan Irak, serta pernah menguasai wilayah yang membentang sejauh 680 kilometer dari Akhtarin di provinsi Aleppo, Suriah, hingga ke Sulaiman Bek, di provinsi Salahaddin, Irak. 
Dalam aksi-aksinya, ISIS memperlihatkan cara-cara kekerasan, antara lain dalam bentuk pembunuhan massal dan pengusiran paksa kelompok-kelompok minoritas. Aksi-aksi mereka direkam dan dipublikasikan secara luas di media sosial dengan dua tujuan. Pertama, untuk mengintimidasi musuh dan menimbulkan kengerian di tengah warga sipil. Kedua, menimbang bahwa ISIS telah menginvestasikan sumber daya yang besar secara profesional untuk propaganda di media sosial dalam berbagai bahasa, publikasi aksi-aksi brutal ini dapat dinilai sebagai upaya untuk memprovokasi kalangan muda untuk bergabung menjadi petempur ISIS (Lister, 2014).

Pada Januari 2014, ISIS merebut kontrol kota Raqqa (Suriah) dan menjadikannya sebagai ibu kota Khilafah Islam. Menurut saksi mata, petempur ISIS di Raqqa sebagian warga lokal, namun ribuan petempur lainnya berasal dari Eropa, AS, Afrika utara, Chechnya, dan negara-negara lain (Megan, 2015).

Sumber pendapatan ISIS adalah penjualan minyak (melalui pasar gelap), penjualan produk pertanian di kawasan yang diduduki, uang tebusan dari aksi-aksi penculikan, sistem pajak internal, dan lain-lain. Hingga Juni 2014, ISIS diperkirakan telah meraup uang lebih dari 12 juta US Dollar per bulan hanya dari aktivitas di kota Mosul (Irak) saja dan rata-rata meraih 2 juta US Dollar per hari dari penjualan minyak dari Suriah dan Irak. Mulai tahun itu pula, terjadi peningkatan signifikan persenjataan ISIS, termasuk Humvees buatan AS, senapan M16, M4, dan M198 (Lister, 2014).

Pada 10 September 2014, AS mengumumkan dibentuknya koalisi internasional untuk mengalahkan ISIS. Namun, operasi militer AS berjalan tidak efektif. Pada September 2015, Rusia atas permintaan Suriah, turut serta dalam perang melawan ISIS. Keterlibatan Rusia banyak memunculkan perubahan besar dalam konflik ini, antara lain direbutnya kembali Palmyra dari tangan ISIS pada Maret 2016. Setahun setelah Rusia membantu tentara Suriah, ISIS kehilangan lebih dari 4600 mil persegi wilayah yang semula didudukinya, serta kehilangan 3500 petempurnya. Sebanyak 586 kota dan desa telah dibebaskan dari ISIS (Yakovenko, 2016).

Pada Desember 2016, wilayah Aleppo timur berhasil dibebaskan dari tangan Al Nusra, Jaish al Islam, dan berbagai kelompok teror non ISIS. Pada November 2017, kota Deir Ez-Zour berhasil direbut kembali dari tangan ISIS dan peristiwa ini menandai kekalahan ISIS di Suriah. Sebelumnya, koalisi AS dan milisi lokal yang didominasi etnis Kurdi juga berhasil merebut kembali kota Raqqa dari tangan ISIS pada Oktober 2017 (CNN, 2017). 


\section{Kelompok-Kelompok Teroris Non-ISIS}

Jabhah Al Nusrah / Hay'at Tahrir Al Sham

Ada ratusan kelompok-kelompok teroris non-ISIS di Suriah, sebagian besarnya berafiliasi dengan AI Qaida. Salah satu yang pernah menjadi kelompok teror terbesar adalah Jabhah Al Nusrah yang mulai angkat senjata sejak Agustus 2011. Petempurpetempur Al Nusrah banyak yang berasal dari jaringan jihad AI Qaida Irak pimpinan Abu Mus'ab Al Zarqawi. Berdirinya AI Nusra dibantu oleh AI Qaida Irak atau Islamic State (sebelum mendeklarasikan ISIS) dan pemimpin IS, Abu Bakar Al Baghdadi yang menunjuk salah satu anggotanya, bernama Abu Muhammad AI Julani sebagai pimpinan Al Nusrah.

Pada 20 November 2012, Al Nusrah bersama sejumlah kelompok jihad, seperti Ahrar Al Sham Kataeb, Liwaa Al tawhiid, Ahrar Souria, Halab Al Shahba, Harakah Al Fajr Al Islamiia, Dar Al Ummah, Liwa'a Jaish Muhammad, Liwa'a Al Nasr, Liwa'a Dar Al Islam, dan lain-lain mendeklarasikan berdirinya Brigade Koalisi Pendukung Khilafah dan sejak itu mengklaim bahwa tujuan 'perjuangan' mereka di Suriah adalah untuk mendirikan khilafah.

Pada akhir 2013, Al Nusrah memisahkan diri dari IS/AI Qaida Irak setelah Al Baghdadi mendeklarasikan ISIS (Islamic State in Iraq and Syria). Al-Julani menolak berjanji setia (bai'at) kepada Al Baghdadi yang mengangkat dirinya sebagai khalifah (Southfront, 2018). Sebelumnya, pada 11 Desember 2012 pemerintah AS menyatakan bahwa Jabhah Al Nusrah adalah nama lain dari Al Qaeda Irak dan memasukkannya dalam daftar organisasi teroris internasional.

Setelah Rusia secara resmi membantu pemerintah Suriah dalam perang melawan teroris, Jabhah Al Nusrah menjadi salah satu target penting serangan Rusia sehingga daerah kekuasaan kelompok ini menjadi semakin berkurang. Al Nusrah kemudian mengambil strategi mengubah nama menjadi Jabhat Fatah Al Sham (JFA) dan menyatakan tidak lagi punya kaitan dengan Al Qaida. Strategi ini diambil untuk menghindari serangan lanjutan dari koalisi Rusia-Suriah (karena JFA tidak dikategorikan sebagai kelompok teroris).

Namun JFA kemudian berkonflik dengan organisasi jihad lainnya, terutama dengan kelompok kuat Ahrar Al Sham, yang sebelumnya pada tahun 2015 adalah partnernya dalam merebut kota Idlib. Sebagian anggota Ahrar Al Sham kemudian bergabung dengan JFA dan kelompok ini mengubah nama menjadi Hayat Tahrir Al Sham (HTS) pada Januari 2017. HTS menyeru agar kelompok-kelompok jihad lainnya 
menggabungkan diri dengan HTS atau akan dihabisi. Melalui strategi ini, HTS berhasil meraih dominasi di tengah berbagai kelompok jihad lainnya. HTS beranggotakan kelompok-kelompok jihad antara lain Jabhat Ansar AI Din, Nur AI Din AI Zenki, Liwa Al Haqq, dan Jaysh al-Sunnah. Saat ini, HTS masih mengontrol beberapa wilayah di Idlib dan Hama (Southfront, 2018).

\section{Free Syrian Army}

Free Syrian Army (FSA) awalnya didirikan di Turki oleh sejumlah desertir militer Suriah. FSA lebih merupakan merk (brand) bagi beberapa kelompok pemberontak Suriah, mulai dari kelompok nasionalis, Ikhwanul Muslimin, dan beberapa jejaring suku-suku di Suriah. FSA mengibarkan bendera Suriah era mandat Perancis, berbeda dengan AI Nusrah atau ISIS yang mengibarkan bendera bertuliskan kalimat ideologis (syahadat, Allah, Muhammad Saw).

Pada 2013, terjadi perpecahan dalam FSA karena adanya rivalitas di antara negara-negara donor, terutama Qatar dan Arab Saudi, sehingga membuat kekuatan FSA di lapangan lebih minim dibandingkan kelompok jihad garis keras (Al Nusrah dan afiliasinya). Menurut dokumen NSA yang bocor ke publik oleh Edward Snowden, pada Maret 2013, FSA melakukan serangan roket ke Suriah sebagai pesanan dari Pangeran Salman bin Sultan (keluarga kerajaan Saudi). Salman menyediakan 120 ton bahan peledak dan persenjataan lainnya dan memberi instruksi untuk'menyalakan' Damaskus (light up Damascus) dan meratakan airport (Murtaza, 2017).

Meskipun pemerintah negara-negara Barat selalu menyebut FSA sebagai kelompok bersenjata 'moderat' (moderate rebels), namun sejak awal FSA menyatakan persetujuannya dengan Al Qaida. Mustafa Al-Sheikh (Ketua Dewan Tinggi Militer FSA) saat diwawancarai Mona Mahmoud mengatakan,

"Al Qaeda saat ini ada di berbagai penjuru Suriah. Mereka bekerja terpisah. Mereka bahkan berada di Aleppo. Kami tidak bekerja sama dengan mereka. Mereka memiliki pasukan Suriah dan Arab [non-Suriah] dan mereka memiliki target tersendiri, serta memiliki senjata sendiri. Mereka kelompok garis keras yang berbeda. Kami tidak berhubungan dengan mereka tetapi kami tidak berkeberatan dengan aksi mereka di mana pun di Suriah" (The Guardian, 2012).

Milisi FSA juga berkali-kali melakukan operasi bersama Al Nusrah. Antara lain, pada 14 Juni 2015 FSA berkerja sama dengan AI Nusra dan afiliasinya untuk merebut wilayah-wilayah di Idlib, termasuk melakukan pembunuhan massal terhadap warga 
sipil pro-pemerintah Suriah dan meledakkan bangunan-bangunan di kawasan itu (Southfront, 2018).

Pada Agustus 2015, FSA membentuk koalisi dari beberapa milisi jihad, antara lain Suqour al-Ghab', Jabhat al-Inqadh al-Muqatila, dan Ahrar Al Darayya, dan diberi nama Jaysh Al Nasr. Pada Desember 2016, Jaysh Al Nasr diketahui menggunakan tank anti-senjata yang diimpor AS dari Bulgaria Desember 2015, yang juga dimiliki ISIS (Joselow, 2017).

Saat ini, FSA bekerja sama dengan tentara Turki tengah menduduki wilayah Afrin, Suriah.

\section{Persenjataan yang Dikuasai Kelompok Teroris Suriah}

Sebuah organisasi independen yang melacak jejak suplai senjata, Conflict Armament Research (CAR), pada Desember 2017 merilis hasil penelitian mereka selama 3 tahun mengenai asal senjata ISIS. Dengan melakukan pelacakan pada nomer serial senjata yang ditemukan pasca terusirnya ISIS dari beberapa medan pertempuran di Irak dan Suriah, CAR menelusuri asal senjata itu dan bagaimana jalur suplai dari produsen ke ISIS. Di antara senjata yang ditemukan adalah senapan mesin buatan China yang dicampur dengan amfetamin, senapan era Nazi Jerman , drone yang dimodifikasi sendiri oleh ISIS di pabrik yang berfasilitas canggih milik ISIS, serta tank anti-misil dari AS.

Menurut hasil penyelidikan CAR, tank anti-misil berjenis 9M111MB-1 (Anti-Tank Guided Weapon Missile Tube) buatan tahun 2015 itu dijual oleh negara produsen, yaitu Bulgaria, kepada militer AS pada 12 Desember 2015. Tank itu ditemukan di tangan ISIS dalam pertempuran antara ISIS melawan tentara Irak di AI Ramadi, 9 Februari 2016. Dengan demikian, tank itu sampai ke tangan ISIS hanya dalam waktu dua bulan dan menurut CAR, singkatnya waktu ini menunjukkan bahwa tidak banyak makelar dalam jalur suplainya. Senjata yang sama, dengan nomer lot yang identik, juga dimiliki oleh Jaysh AI Nasr (Joselow, 2017).

CAR juga menemukan bahwa ISIS menyimpan zat kimia bernama Sorbitol dalam jumlah sangat banyak di pabrik-pabriknya. Sorbitol merupakan salah satu zat yang dibutuhkan untuk membuat bahan bakar roket. Kantong-kantong penyimpan sorbitol ini berlabel perusahaan Perancis, Tereos, dan sampai ke tangan ISIS melalui Turki pada 2015. 
The Guardian (2016) yang mengutip laporan dari Balkan Investigative Reporting Network (BIRN) dan Organised Crime and Corruption Reporting Project (OCCRP) menyebutkan bahwa negara-negara Eropa timur, seperti Bosnia, Bulgaria, Kroasia, Republik Ceko, Montenegro, Slovakia, Serbia dan Romania telah melakukan penjualan senjata senilai lebih dari 1 miliar Euro kepada negara-negara Timur Tengah yang kemudian diketahui mengirimkan persenjataan itu ke Suriah. Senjatasenjata itu berupa senapan serbu seperti AK-47, cangkang mortir (mortar shells), peluncur roket, tank anti senjata, dan senjata mesin berat (heavy machine guns) telah dikirimkan dari negara-negara Balkan menuju semenanjung Arab dan negaranegara yang berbatasan dengan Suriah.

Berikut ini tabel yang menunjukkan nilai transaksi penjualan senjata dari negara-negera Eropa Timur ke beberapa negara di Timur Tengah

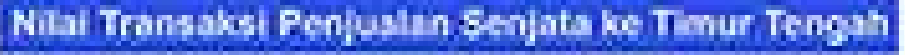

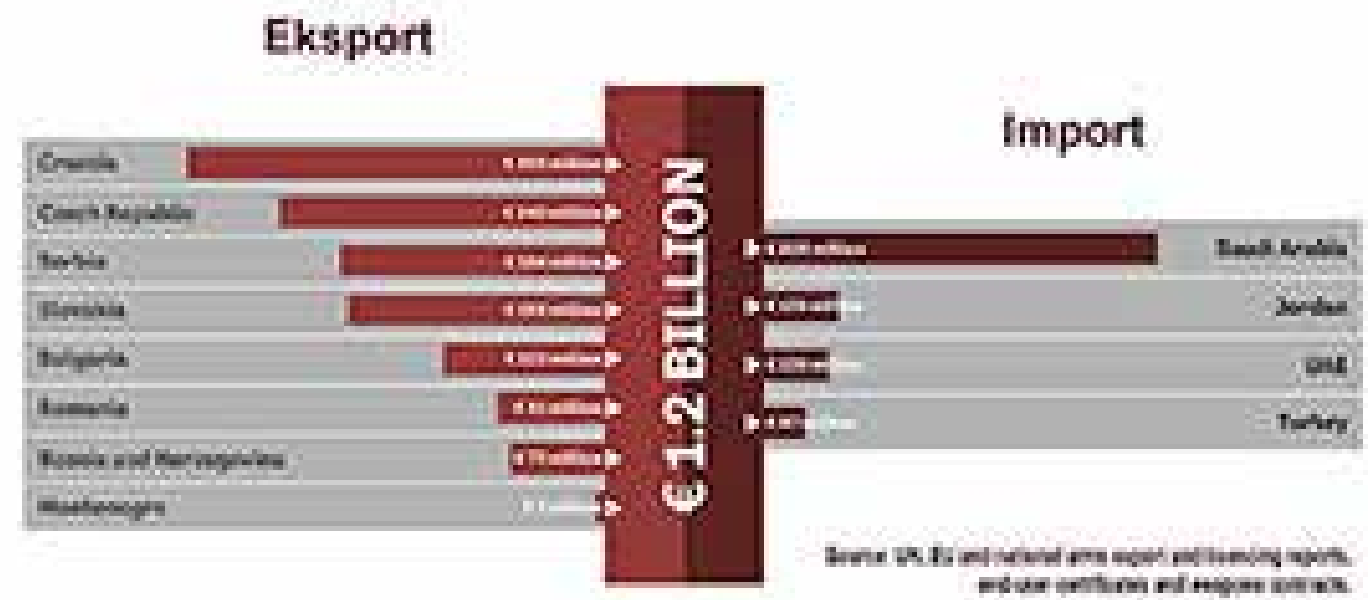

Sumber: Marzouk (2016a)

Menurut laporan ini, persenjataan itu kini dimiliki FSA, Al Nusrah, Ansar AI Sham, dan ISIS, dan jalur suplainya melalui Arab Saudi dan Qatar. Selain itu, laporan BIRN dan OCCRP menyebutkan bahwa sejak eskalasi konflik Suriah pada 2012 hingga 2016, ada delapan negara yang menyepakati ekspor senjata senilai 1,2 miliar Euro, dengan perincian sebagai berikut. Senjata senilai 806 juta Euro diekspor ke Arab Saudi, 155 juta Euro ke Yordania, 135 juta Euro ke Uni Emirat Arab, dan 87 juta Euro ke Turki. Di masa lalu, negara-negara ini tidak memiliki catatan pernah membeli senjata dari Eropa tengah dan timur. Jalur suplai senjata dari Eropa timur ke Suriah pertama kali dibuat pada musim dingin 2012, ketika lusinan pesawat kargo yang membawa senjata pesanan Saudi lepas landas dari Zagreb menuju Yordania; dan segera setelah 
itu muncul video pertama yang memperlihatkan kelompok teroris Suriah sedang menggunakan senjata buatan Kroasia.

Berikut ini tabel rute suplai senjata dari Balkan ke Timur Tengah yang dilaporkan BIRN dan OCCRP.

\begin{tabular}{|l|l|l|l|}
\hline No & Asal & Tujuan & Jumlah Penerbangan \\
\hline 1 & \multirow{3}{*}{ Bratislava } & Tabuk (Saudi) & 14 \\
\cline { 3 - 4 } & & Prince Sultan Airbase (Saudi) & 2 \\
\cline { 3 - 4 } & & Amman (Yordania) & 1 \\
\hline 2 & \multirow{3}{*}{ Belgrade } & Jeddah & 29 \\
\cline { 3 - 4 } & & Prince Sultan Airbase (Saudi) & 2 \\
\cline { 3 - 4 } & & Sharurah (Saudi) & 1 \\
\cline { 3 - 4 } & & Abu Dhabi (UAE) & 8 \\
\hline 3 & \multirow{2}{*}{ Nis } & Amman & 1 \\
\cline { 3 - 4 } & & Jeddah & 1 \\
\hline 4 & Sofia & Jordan & 6 \\
\hline 5 & Burgas & Abu Dhabi & 1 \\
\hline
\end{tabular}

Tabel Diadaptasi dari Marzouk (2016a)

Jauh sebelumnya, yaitu Februari 2013, The New York Times pertama kali melaporkan bahwa Arab Saudi menyuplai senjata kepada pemberontak Suriah dengan persenjataan yang dibeli dari Kroasia. Menurut NYT, konsultan CIA berperan membantu negara-negara Arab dan Turki untuk mengirimkan persenjataan ke Suriah, ketika di saat yang sama posisi resmi Washington adalah menolak pengiriman senjata tersebut. Persenjataan itu dibawa dengan pesawat lebih dari 160 penerbangan kargo Yordania, Arab Saudi, dan Qatar, yang mendarat di Airport Esenboga, Turki, serta di beberapa airport Yordania (Dettmer, 2013).

Menurut laporan terbaru pada April 2017, suplai senjata dari Saudi ke kelompok teroris masih berlangsung. Laporan yang melacak data dari marinetraffic.com ini menyebutkan, sebuah kapal kargo berbendera Denmark bernama Marianne Danica telah mendarat di pelabuhan Arab Saudi pada 6 April 2017. Kapal itu berangkat dari Burgas (Bulgaria) pada 28 Maret 2017 berisi berton-ton senjata dan bahan peledak. Persenjataan ini dipastikan tidak akan dipakai oleh militer Saudi karena Saudi hanya 
menggunakan senjata buatan Barat. Pelacakan selanjutnya menemukan bahwa perusahaan bernamaVMZ-Sopotmemiliki kontrakdengan dua perusahaan AS, Chemring dan Orbital ATK. Pada tahun 2016 saja, Chemring memiliki kontrak senilai 47 juta US Dollar untuk menyuplai senjata yang tidak kompatibel dengan sistem persenjataan AS (antara lain, senjata buatan Bulgaria). Orbital ATK juga menerima kontrak untuk program senjata yang sama senilai 50 juta US Dollar. Karena baik AS dan Arab Saudi tidak menggunakan persenjataan yang diimpor tersebut, dapat disimpulkan bahwa senjata itu disalurkan kepada milisi bersenjata di Suriah (SOL, 2017).

Namun demikian laporan dari CAR menunjukkan secara keseluruhan, persenjataan yang ada di tangan ISIS sebagian besarnya (50\%) adalah buatan China dan Rusia. Hal ini terjadi karena kedua negara tersebut adalah suplier bagi militer Suriah dan Irak, kemudian ISIS dalam berbagai pertempuran merebut persenjataan tersebut. Selain itu, persenjataan yang dimiliki ISIS juga ditransfer dari cadangan senjata Libya (CAR, 2017) dan perusahaan China dilaporkan pernah menjual senjata kepada Qaddafi meskipun secara resmi pemerintah China membantah hal tersebut (The Guardian, 2011). Pasca tumbangnya Qaddafi, menurut dokumen PBB, telah terjadi transfer senjata yang dilakukan milisi AI Qaida Libya kepada milisi jihad Suriah yang juga berafiliasi dengan Al Qaida (Nichols, 2013).

\section{Pelanggaran Terhadap Arms Trade Treaty}

Perangyang terjadiantara tentara nasional Suriah melawan milisi-milisibersenjata yang terafiliasi dengan AI Qaida dan ISIS telah menimbulkan kerusakan fisik dan nonfisik yang sangat besar. Menurut PBB (2018), perang ini telah menyebabkan tewasnya 400.000 orang dan melukai lebih dari 1 juta orang, serta memaksa lima juta warga mengungsi ke luar Suriah (UN, 2018).

Pada bulan Oktober 2017, untuk pertama kalinya, Kementerian Luar Negeri AS mengeluarkan pengakuan mengenai detil kejahatan kemanusiaan yang dilakukan oleh kelompok-kelompok teroris di Suriah. Dalam travel warning yang dirilis Kementerian Luar Negeri AS disebutkan:

Teroris dan kelompok ekstrimis kekerasan lainnya, termasuk ISIS dan Hay'at Tahrir Al Sham yang berafiliasi dengan AI Qaida, beroperasi di Suriah. Taktik yang mereka lakukan termasuk bom bunuh diri, penculikan, penggunaan senjata ringan dan berat, alat ledak yang diimprovisasi, dan senjata kimia. Kelompokkelompok teror itu menargetkan penghalang jalan, perbatasan, bangunan 
pemerintah dan area-area publik di kota-kota seperti Damaskus, Aleppo, Hama,

Daraa, Homs, Idlib, dan Deir-ez-Zor (RT, 2017).

Kelompok-kelompok teroris di Suriah bersenjata sangat lengkap dan bergerak di berbagai penjuru Suriah sehingga menyulitkan pemerintah Suriah dalam menanganinya. Akibatnya, perang telah berlangsung hingga enam tahun dan masih belum bisa diprediksi kapan akan berakhir. Salah satu penyebab utama terus terjadinya perang adalah karena suplai senjata kepada Non-State Actor (NSA).

Perdagangan senjata kepada NSA telah berkontribusi terhadap berbagai konflik dan ketidakamanan di seluruh dunia. Perhatian komunitas internasional terhadap fenomena ini telah muncul sejak tahun 1990-an. Pasca Perang Dingin, telah terjadi transfer senjata konvensional kepada kelompok-kelompok bersenjata di Afghanistan, Lebanon, Libya, Sri Lanka, Yaman, juga kepada perusahaan-perusahaan militer swasta (private military companies). Mereka tidak hanya menguasai senjata ringan, tetapi juga helikopter, kendaraan bersenjata (armoured vehicles), dan berbagai jenis senjata berat lainnya. Sejumlah LSM dan negara memandang fenomena penguasaan senjata oleh NSA sebagai ancaman atas perdamaian, keamanan, dan kestabilan dunia (Holtom, 2012). Setelah melalui proses panjang, pada 24 Desember 2014 perjanjian Arms Trade Treaty (ATT) diberlakukan di dunia.

\section{Sejarah Arms Trade Treaty (ATT)}

Upaya menggalang dukungan terhadap ATT dimulai pada tahun 1997 oleh Presiden Costa Rica dan pemenang hadiah Nobel Perdamaian, Oscar Arias. Pada tahun itu, Arias memimpin pertemuan sekelompok penerima hadiah Nobel Perdamaian yang merekomendasikan agar PBB membuat aturan penjualan senjata. Pada Juli 1998, wakil dari 21 negara bertemu di Oslo dimana pemerintah Kanada menyampaikan proposal'Konvensi Global Pencegahan Transfer Internasional Senjata Militer Kecil dan Senjata Ringan kepada Non-State Actors'. Proposal ini menekankan pentingnya mengontrol transfer senjata ringan agar tidakjatuh ke tangan yang salah. Namun saat itu sejumlah negara dan LSM menolak proposal ini dengan alasan, ada NSA yang memerlukannya sebagai satu-satunya pilihan untuk melawan pemerintah mereka yang represif.

Proposal untuk pencegahan transfer senjata global kepada NSA juga diangkat pada Konferensi PBB mengenai Perdagangan llegal Senjata Ringan (the United Nations Conference on the Illicit Trade in Small Arms and Light Weapons in All Its Aspects) yang berlangsung pada 9-20 Juli 2001. Dalam konferensi itu ditekankan bahwa negara- 
negara produsen senjata hanya boleh menjual senjata mereka kepada pemerintah, baik langsung maupun melalui badan lain yang bertindak mewakili negara (Holtom, 2012).

Kemudian tahun 2012, ATT dinegosiasikan kembali di PBB, yang dilanjutkan pada tanggal 18-28 March 2013. Akhirnya, pada 2 April 2013, Majelis Umum PBB mengadopsi ATT. Kesepakatan ini diberlakukan mulai 24 Desember 2014 dan telah diratifikasi oleh 94 negara, termasuk lima negara besar produsen senjata, yaitu Inggris, Perancis, Jerman, Italia, dan Spanyol. Sementara itu, ada 41 negara yang sudah menandatangani ATT namun tidak meratifikasinya, termasuk AS yang merupakan produsen terbesar senjata dunia. Negara-negara produsen senjata besar lainnya, China, Russia, India and Pakistan juga belum menandatangani ATT (ATT, 2014).

Dalam pidato menyambut diberlakukannya ATT, Sekjen PBB Ban Ki-moon menyatakan harapannya bahwa ATT akan membantu mencegah penyaluran senjata kepada para pemimpin perang (warlords), pelanggar HAM, dan organisasi kriminal. Menurut Ban Ki-moon, diberlakukannya ATT "menandai fase baru dalam upaya kolektif global untuk membawa tanggung jawab, akuntabilitas, dan transparansi dalam penjualan senjata global." Bisnis global perdagangan senjata diperkirakan bernilai 85 miliar US Dollar per tahun, meskipun sebagian analis menilai jumlah sebenarnya lebih tinggi (BBC, 2014).

\section{Dilema dalam Arms Trade Treaty}

a. Penentuan Non-State Actors Terkait Kepemilikan S enjata

Menurut Holtom (2012), kelompok-kelompok yang masuk kategori NSA yang berkaitan atau memerlukan senjata adalah sebagai berikut.

- kelompok pemberontak bersenjata, 'pejuang kemerdekaan', paramiliter, atau para komandan perang

- paramiliter dan NSA lainnya yang terkait dengan lembaga pemerintah

- milisi sipil, termasuk kelompok komunal dan milisi pertahanan sipil, kelompok siaga

- $\quad$ teroris dan organisasi teroris

- pelaku kriminal dan kelompok kriminal, termasuk pedagang senjata di pasar gelap

- partai politik dan kelompok politik yang terkait

- perusahaan militer swasta 
- perusahaan keamanan swasta dan perusahaan swasta yang memiliki petugas keamanan

- pedagang senjata, baik pengecer domestik yang legal, pedagang, maupun distributor

- makelar penjualan senjata, front companies institusi sipil, misalnya museum (yang membutuhkan pengamanan bersenjata)

- warga sipil, seperti olahragawan tembak, pemburu, kolektor senjata, dan sipil pemegang izin kepemilikan senjata

Penetapan mengenai NSA mana yang perlu dilarang mendapatkan senjata merupakan salah satu sumber perdebatan dalam ATT. Dalam konferensi ATT, pejabat AS, John Bolton (saat itu menjabat sebagai wakil AS untuk urusan pengontrolan senjata dan keamanan internasional) menyatakan penolakannya dengan alasan "proposal ini akan menghalangi bantuan kepada NSA yang membela diri di hadapan pemerintahan yang melakukan pembantaian massal. Pembedaan antara pemerintah dan NSA tidak relevan dengan bertanggung jawab atau tidaknya pengguna akhir senjata itu" (Holtom, 2012).

\section{b. Dilema Kepentingan Negara-Negara Produsen Senjata}

Pernyataan John Bolton mengenai 'NSA yang membela diri di hadapan pemerintah yang melakukan pembunuhan massal'memunculkan ketidaksepakatan lain mengenai identifikasi pemerintah seperti apa yang masuk dalam kategori demikian. Dilema ini muncul karena perbedaan kepentingan di antara negaranegara besar pemegang hak veto yang di saat yang sama juga merupakan negara produsen senjata terbesar di dunia.

Dalam kasus Libya 2011, Dewan Keamanan PBB mengeluarkan Resolusi No. 1973 yang menyatakan, negara-negara anggota PBB harus 'melakukan segala hal yang diperlukan untuk melindungi warga sipil'. Resolusi ini keluar hanya sebulan setelah pihak pemberontak Libya yang berafiliasi dengan Al Qaida mengklaim bahwa rezim Qaddafi melakukan pembunuhan massal dan karena itu, mereka meminta bantuan internasional. AS, Perancis, dan Inggris memaknai Resolusi PBB ini sebagai izin pengiriman senjata dan konsultan militer kepada milisi-milisi antiQaddafi. Sebaliknya, Rusia dan China memandang tindakan tersebut bertentangan dengan Resolusi PBB 1973 dan melanggar Deklarasi Majelis Umum PBB mengenai Prinsip Hukum Internasional terkait Hubungan Persahabatan Antarnegara, dimana 
dukungan kepada aksi bersenjata yang bertujuan menggulingkan pemerintahan atau ikut campur dalam konflik sipil di negara lain adalah hal yang dilarang. Namun akhirnya, mulai 19 Maret 2011 NATO membombardir Libya dan berlangsung hingga 31 Oktober 2011 setelah Qaddafi tewas.

Pada tahun 2012, Panel Pakar PBB untuk Libya mengungkapkan bahwa menurut Menteri Pertahanan Pemerintahan Transisi Libya, Qatar dan Sudan telah menyuplai senjata dan perlengkapan militer kepada pasukan anti-Qaddafi.Qatarjuga menyuplai amunisi buatan Swiss (Holtom, 2012). Sebaliknya, China diberitakan menyuplai senjata kepada rezim Qaddafi pada 2011 berdasarkan dokumen yang menunjukkan bahwa perwakilan perusahaan senjata China (China North Industries CorporationNorinco) bertemu dengan perwakilan pemerintah Qaddafi pada Juli 2011 dimana China menawarkan penjualan senjata senilai 200 juta US Dollar. Penjualan ini dianggap illegal karena saat itu Libya sedang diembargo senjata oleh PBB.

Dalam kasus Suriah, dilema juga terjadi ketika kedua kubu memiliki perbedaan persepsi mengenai pemerintah Suriah. AS, Inggris, dan Perancis berkeras menyatakan bahwa rezim Assad melakukan kejahatan kemanusiaan kepada warga sipil dan atas dasar itulah mereka menyuplai senjata kepada NSA (milisi-milisi bersenjata) di Suriah. Sebaliknya, Rusia dan China mengambil sikap yang sejalan dengan pemerintah Suriah, yaitu menempatkan NSA di Suriah sebagai kelompok teroris karena mereka berjejaring dengan AI Qaida (sebagaimana telah diuraikan sebelumnya di artikel ini). Dengan demikian, dalam pandangan Rusia dan China, pengiriman senjata kepada NSA di Suriah adalah illegal.

Dalam konflik Suriah, AS diketahui telah mengeluarkan dana sebesar 2,2 miliar US Dollar untuk membeli senjata dari Eropa timur yang kemudian disalurkan kepada para teroris di Suriah. BIRN dan OCCRP dengan mengumpulkan catatan pengadaan barang, data pelacakan kapal, laporan resmi, email pejabat yang bocor, serta wawancara terhadap 'orang dalam', menemukan bahwa Pentagon telah membeli senjata melalui dua jalur, yaitu SOCOM dan the Picatinny Arsenal. SOCOM (Special Operations Command) adalah lembaga yang mengawasi seluruh operasi khusus dalam militer AS dan Picatinny Arsenal adalah fasilitas senjata militer AS di New Jersey. Senjata yang dibeli Pentagon (Kementerian Pertahanan AS) dikirimkan lewat laut dan udara dari Eropa ke Turki, Yordania, dan Kuwait, lalu disalurkan kepada sekutu-sekutu AS di utara dan selatan Suriah dengan menggunakan pesawat dan truk (Angelovski dan Marzouk, 2017). 
Meskipun AS bukan para pihak ATT, namun tindakan tersebut telah melanggar Undang-Undang AS sendiri. Tulsi Gabbard, anggota Parlemen AS dari Partai Republik, menyatakan bahwa oposisi Suriah yang dibantu AS terbukti sebagai organisasi teroris (ISIS dan Al Qaida) sehingga pengiriman senjata kepada mereka adalah pelanggaran terhadap UU AS yang melarang memberikan bantuan apapun kepada teroris (Gabbard, 2016).

Berikut ini tabel yang menunjukkan nilai pembelian senjata yang dilakukan Kementerian Pertahanan AS kepada Negara-negara Timur Tengah, yang dilacak OCRP dari US Federal Procurement Data System (FPDS.gov) and Enigma.io.

\section{Pembelian Senjata untuk Pemberontak Suriah oleh Pentagon}

\begin{tabular}{lll}
\hline Nomor & Negara Produsen Senjata & $\begin{array}{l}\text { Nilai Pembelian } \\
\text { (dalam milyar dollar) }\end{array}$ \\
\hline 1 & Bulgaria & 234.3 \\
2 & Unknown & 135.6 \\
3 & Afghanistan & 126.5 \\
4 & Czech Republic & 69.3 \\
5 & Romania & 38.7 \\
6 & Serbia & 33.2 \\
7 & Bosnia and Herzegovina & 32.5 \\
8 & Ukraine & 17.3 \\
9 & Poland & 9.4 \\
10 & Croatia & 6.3 \\
11 & Kazakhstan & 4.0 \\
12 & Georgia & 1.8 \\
\hline
\end{tabular}

Tabel diadaptasi dari OCRP (2016)

Di sisi lain, Rusia dan China menjual senjata kepada militer Suriah ( $G$ to G) sehingga tidak termasuk dalam pembatasan yang diatur ATT. Bahkan bagi Rusia, perang Suriah menjadi 'pentas pameran' senjata produksinya, mulai dari jet pengebom Sukhoi Su-32, stasiun pengacak komunikasi, rudal S-400, tank, sistem pertahanan udara, senjata ringan, dan kapal selam. Moscow memperkirakan akan terjadi peningkatan penjualan senjata buatan Rusia ke berbagai negara dunia hingga 7 miliar US Dollar (Aljazeera, 2016).

\section{Aturan dalam Arms Trade Treaty}

Senjata-senjata yang diatur pergerakannya oleh ATT adalah sebagai berikut. 
(1) Tujuh kategori senjata yang telah diatur oleh UN Register of Conventional Arms, yaitu tank tempur, kendaraan bersenjata (armoured combat vehicles), sistem artileri berkaliber besar (large-calibre artillery systems), pesawat tempur, helikopter tempur, kapal tempur, serta misil dan peluncur misil.

(2) SALW (small arms and light arms), dengan definisi sebagai berikut.

(a) 'Small arms' are, broadly speaking, weapons designed for individual use. They include, inter alia, revolvers and self-loading pistols, rifles and carbines, sub-machine guns, assault rifles and light machine guns;

(b) 'Light weapons' are, broadly speaking, weapons designed for use by two or three persons serving as a crew, although some may be carried and used by a single person. They include, inter alia, heavy machine guns, handheld under-barrel and mounted grenade launchers, portable anti-aircraft guns, portable anti-tank guns, recoilless rifles, portable launchers of antitank missile and rocket systems, portable launchers of antiaircraft missile systems, and mortars of a calibre of less than 100 millimetres.

(3) Ammunition and Munition

"[Ammunition] is a complete device, (e.g. missile, shell, mine, demolition store etc.) charged with explosives, propellants, pyrotechnics or initiating composition for use in connection with offence, or defence, or training, or non $\square$ operational purposes, including those parts of weapons systems containing explosives. (c.f. munition).

"[Munition] is a complete device charged with explosives, propellants, pyrotechnics, initiating composition, or nuclear, biological or chemical material for use in military operations, including demolitions."

(4) Parts and Components

"Parts and components shall mean any element or replacement element specifically designed for a firearm and essential to its operation, including a barrel, frame or receiver, slide or cylinder, bolt or breech block, and any device designed or adapted to diminish the sound caused by firing a firearm." (UNODA, 2013). 
ATT mewajibkan negara-negara para pihak (States Parties) untuk membangun dan mempertahankan sistem kontrol ekspor nasional mereka agar selalu sejalan dengan aturan ekspor dalam ATT, termasuk penerapan asesmen ekspor dan larangan ekspor senjata apabila melanggar aturan ATT.

Negara-negara para pihak juga diwajibkan menyusun UU nasional yang dengan jelas menyatakan hal-hal berikut ini:

a) senjata apa saja yang masuk daftar kontrol ekspor

b) kementerian atau agen apa dalam pemerintah yang bertanggung jawab mengontrol ekspor senjata

c) kriteria dalam mengizinkan atau menolak ekspor senjata (prosedur regulasi)

d) sanksi yang diberikan bila terjadi pelanggaran

Negara-negara para pihak ATT diwajibkan menolak ekspor senjata bila:

a) melanggar aturan-aturan $\mathrm{PBB}$, termasuk di antaranya aturan mengenai embargo

b) melanggar perjanjian internasional

c) diketahui bahwa senjata itu akan digunakan untuk genosida, kejahatan kemanusiaan, pelanggaran Konvensi Jenewa 1949, menyerang warga sipil atau objek sipil, dan kejahatan perang lainnya yang diatur dalam perjanjian internasional.

Jika ekspor senjata tersebut tidak melanggar aturan di atas, negara produsen senjata tetap diminta untuk meneliti terlebih dahulu, apakah ekspor yang akan dilakukan berperan dalam menciptakan perdamaian, ataukah akan membahayakan perdamaian; atau apakah senjata itu ada kemungkinan untuk digunakan dalam halhal berikut:

(i) melakukan atau memfasilitasi pelanggaran serius terhadap hukum hak asasi manusia internasional;

(ii) melakukan atau memfasilitasi suatu tindakan yang merupakan pelanggaran terhadap konvensi internasional atau protokol yang berkaitan dengan terorisme dimana negara pengekspor adalah para pihak;

(iii) melakukan atau memfasilitasi suatu tindakan yang merupakan pelanggaran terhadap konvensi internasional atau protokol yang berkaitan dengan 
kejahatan terorganisir transnasional dimana negara pengekspor adalah para pihak; atau

(iv) memfasilitasi tindakan kekerasan berbasis gender yang serius, terhadap perempuan dan anak-anak.

Dari sebagian aturan-aturan yang ditetapkan dalam ATT, terlihat bahwa pengiriman senjata yang dilakukan sebagian negara kepada milisi-milisi teroris (NSA) di Suriah merupakan pelanggaran. Beberapa negara yang telah disebutkan perannya dalam pengiriman senjata ke NSA Suriah di artikel ini adalah para pihak dalam ATT, yaitu Bulgaria, Kroasia, Ceko, Slovakia, dan Denmark. Sementara itu, negara pembeli, yaitu Qatar, Arab Saudi, UAE, Turki, dan AS tidak menandatangani ATT (ATT, 2018).

Laporan penelitian BIRN menyebutkan meskipun ada larangan ekspor ke negara-negara yang diembargo, masing-masing surat permohonan izin ekspor ditangani secara individual. Akibatnya, pemberian izin ekspor sangat bergantung kepada apakah negara produsen telah melakukan pemeriksaan secara menyeluruh, termasuk pada kemungkinan senjata-senjata itu dialihkan ke pihak ketiga dan bagaimana dampak ekspor terhadap perdamaian dan keamanan.

BIRN dan OCCRP mewawancarai pejabat Kroasia, Cheko, Montenegro, Serbia, dan Slovakia, dan mereka semua menyatakan sudah memenuhi kewajiban sebagai para pihak ATT, yaitu melakukan asesmen terhadap negara pengimpor senjata mereka. Mereka menyatakan bahwa Arab Saudi bukan negara yang diembargo, sehingga tidak ada masalah dalam transaksi jual-beli senjata tersebut. Sementara itu, tiga negara lainnya tidak memberikan respon atas permintaan wawancara dari BIRN dan OCCRP.

BIRN dan OCCRP meneliti dokumen Kementerian Pertahanan Serbia tahun 2013 yang menyebutkan bahwa kementerian khawatir senjata yang diimpor Arab Saudi akan dialihkan ke Suriah dengan alasan Saudi selama ini tidak menggunakan senjata buatan Eropa tengah dan timur; serta memiliki rekam jejak sebagai penyuplai senjata kepada oposisi Suriah. Pada tahun itu, Kementerian Pertahanan Serbia menolak permintaan ekspor ke Saudi. Namun tahun berikutnya Serbia menyetujui ekspor dengan alasan 'kepentingan nasional'.

Meskipun ATT berisi aturan bahwa para pihak dapat menghentikan ekspor senjata yang beresiko, namun tidak ada kewajiban yang mengikat. Mereka hanya diminta untuk 'mengambil langkah yang tepat' bila ternyata senjata yang mereka ekspor dialihkan ke pihak yang tidak berhak menerimanya. Namun tidak dijelaskan seperti apa 'langkah yang tepat' (appropriate measures) itu (Marzouk, 2016a). 
Fenomena ini menunjukkan bahwa ATT tidak atau belum efektif diimplementasikan dalam kasus Suriah dan inilah yang menjadi salah satu penyebab utama eskalasi dan kontinuitas konflik. Terutama karena negara-negara pendukung NSA atau kelompok-kelompok teroris di Suriah justru bukan para pihak ATT dan mereka yang menjadi penyuplai utama persenjataan NSA di Suriah. Sementara itu pihak produsen tidak melakukan kewajibannya untuk melakukan asesmen mengenai potensi digunakannya senjata yang mereka ekspor untuk hal-hal yang membahayakan perdamaian dan aksi-aksi terorisme.

\section{Kesimpulan}

Konflik Suriah yang telah berjalan enam tahun melibatkan ratusan kelompok bersenjata yang melakukan aksi-aksi kekerasan terhadap warga sipil, mulai dari bom bunuh diri hingga meluncurkan misil ke daerah-daerah padat penduduk. Aksi seperti ini merupakan aksi terorisme yang ditentang oleh komunitas internasional. Rekam jejak kelompok-kelompok bersenjata atau NSA di Suriah juga memperlihatkan keterkaitan mereka dengan AI Qaida. Secara resmi, PBB telah memasukkan AI Qaida dan beberapa NSA di Suriah sebagai organisasi teroris.

Salah satu kekuatan utama dari resistensi NSA Suriah adalah terus mengalirnya suplai senjata kepada mereka. Kondisi serupa juga terjadi dalam berbagai konflik di dunia selama ini, di mana konflik terus-menerus berlangsung akibat keterjagaan suplai senjata. Komunitas internasional sejak tahun 1990-an telah menyatakan pentingnya upaya kolektif global untuk menjaga tanggung jawab, akuntabilitas, dan transparansi dalam penjualan senjata agar tidak jatuh ke tangan teroris, organisasi teroris, organisasi kriminal, dan kelompok non-state bersenjata lainnya.

Setelah melalui proses panjang, akhirnya Majelis Umum PBB menyepakati diberlakukannya Arms Trade Treaty (ATT) pada 24 Desember 2014 yang mengatur penjualan senjata terutama kepada NSA. Namun sayangnya, implementasi ATT belum maksimal, terutama dalam kasus Suriah. Sejumlah negara, baik para pihak ATT maupun negara yang tidak menjadi penandatangan masih terus melanjutkan penjualan dan pembelian senjata untuk kemudian disalurkan kepada NSA di Suriah, termasuk kelompok-kelompok teroris seperti ISIS dan AI Nusrah (dan afiliasinya). Akibatnya, perang di Suriah masih terus berlangsung meski sudah berlangsung enam tahun. 
Untuk itu, dunia internasional perlu lebih serius melakukan upaya-upaya dalam menangani masalah ini, termasuk di antaranya menekan negara-negara produsen dan pembeli senjata yang kemudian disuplai kepada teroris di Suriah.

\section{Daftar Pustaka}

Aljazeera. (2016). Syria's war: A showroom for Russian arms sales. [online] Dalam: https://www.aljazeera.com/news/2016/04/syria-war-showroom-russian-armssales-160406135130398.html. [Diakses 13 April 2018].

Angelovski dan Marzouk. (2017). The Pentagon is Spending 2 Billio on Soviet Style for Syrian Rebels. [online] OCCRP. Dalam: https://www.occrp.org/en/makingakilling/ the-pentagon-is-spending-2-billion-on-soviet-style-arms-for-syrian-rebels [Diakses 13 April 2018].

ATT (Arms Trade Treaty). (2014). Arms Trade Treaty. [online] Dalam: http://www. thearmstradetreaty.org/index.php/en/the-arms-trade-treaty [Diakses 13 April 2018].

ATT. (2018). List of State Parties. [online] Dalam: http://www.thearmstradetreaty. org/images/Status_lists/List_of_ATT_States_Parties_by_order_of_deposit26_ January_2018.pdf [Diakses 13 April 2018].

BBC. (2014). Global arms trade deal takes effect. [online] Dalam: http://www.bbc.com/ news/world-30594854. [Diakses 13 April 2018].

CAR (Conflict Armament Research). (2017). Weapons of ISIS. [online] Conflict Arm. Dalam: $\quad$ www.conflictarm.com/download-file/?report_id=2568\&file_id=2574 [Diakses 13 April 2018].

Gabbard, T. (2016). Video Rep. Tulsi Gabbard Introduces Legislation Stop Arming Terrorists. [online] Gabbard House. Dalam: https://gabbard.house.gov/news/ press-releases/video-rep-tulsi-gabbard-introduces-legislation-stop-armingterrorists. [Diakses 13 April 2018]

Gillis, M. (2017). Disarmament: A Basic Guide. New York: UNODA.

Hassan, H. (2017). The story of Hayat Tahrir Al Sham's rise to prominence and what it means for Syria. The National, [online] The National. Dalam: https://www. thenational.ae/opinion/the-story-of-hayat-tahrir-al-sham-s-rise-to-prominenceand-what-it-means-for-syria-1.614506 [Diakses 13 April 2018]. 
Holtom, P. (2012). Prohibiting Arms Transfers to Non-State Actors and the Arms Trade Treaty. Switzerland: Stockholm International Peace Research Institute

HRW (Human Rights Watch). (2018). Libya: Events of 2017. [online] HRW. Dalam: https://www.hrw.org/world-report/2018/country-chapters/libya [Diakses 5 Mei 2018].

Joselow, G. (2017). ISIS weapons arsenal included some purchased by U.S. government NBC News, [online]. Dalam: https://www.nbcnews.com/news/world/isisweapons-arsenal-included-some-purchased-u-s-government-n829201 [Diakses 5 Mei 2018].

Kifner, J. (2000). Syrians Vote To Confirm Assad's Son As President. New York Times, [online]. Dalam: https://www.nytimes.com/2000/07/11/world/syrians-vote-toconfirm-assad-s-son-as-president.html [Diakses 5 Mei 2018].

Lister, C. (2014). Assessing Syria's Jihad, Survival. Global Politics and Strategy, [online] 56 (6), 7-112. DOI: 10.1080/00396338.2014.985439 [Diakses 5 Mei 2018].

Ma'oz, M. (2014) The Arab Spring in Syria: Domestic and regional developments, Dynamics of Asymmetric Conflict: Pathways toward terrorism and genocide, [online] 7 (1), 49-57. DOI: 10.1080/17467586.2014.894249 [Diakses 5 Mei 2018].

Marzouk, L., Angelovski, I., dan Patrucic, M. (2016a). Making a Killing: The 1.2 Billion Euro Arms Pipeline to Middle East. [online] Balkan Insight. Dalam: http://www. balkaninsight.com/en/article/making-a-killing-the-1-2-billion-euros-armspipeline-to-middle-east-07-26-2016 [Diakses 5 Mei 2018].

Marzouk, L., Angelovski, I., dan Patrucic, M. (2016b). Revealed: the $£ 1$ bn of weapons flowing from Europe to Middle East. The Guardian, [online] Dalam: https://www. theguardian.com/world/2016/jul/27/weapons-flowing-eastern-europe-middleeast-revealed-arms-trade-syria [Diakses 5 Mei 2018].

Murtaza, H. (2017). NSA Document Says SaudiPrince Directly Ordered Coordinated Attack By Syrian Rebels On Damascus. [online] Intercept. Dalam: https://theintercept. com/2017/10/24/syria-rebels-nsa-saudi-prince-assad/ [Diakses 5 Mei 2018].

Nichols, M. (2013). Libya arms fueling conflicts in Syria, Mali and beyond: U.N. experts. Reuters, [online] Dalam: https://www.reuters.com/article/us-libyaarms-un/libya-arms-fueling-conflicts-in-syria-mali-and-beyond-u-n-expertsidUSBRE93814Y20130409 [Diakses 5 Mei 2018]. 
OCCRP. (2016). Making a Killing, The Infographics. [online] Dalam: https://www.occrp. org/en/makingakilling/infographics [Diakses 20 April 2018].

RT. (2017). State Department Chemical Weapons Syria. [online] Dalam: https://www. rt.com/usa/407267-state-department-chemical-weapons-syria/ [Diakses 20 April 2018].

SOL. (2017). How al-Nusra jihadists in Syria receive weapons? [online] SOL. Dalam: https://news.sol.org.tr/how-al-nusra-jihadists-syria-receive-weapons-172119 [Diakses 5 Mei 2018].

Southfront. (2018). Hayat Tahrir al-Sham: History, Capabilities, Role In Syrian War. [online] Dalam: https://southfront.org/hayat-tahrir-al-sham-history-capabilitiesrole-in-syrian-war/ [Diakses diakses 5 Mei 2018].

Specia, M. (2015). The Taking of Raqqa. [online] Mashable. Dalam: https://mashable. com/2015/08/04/the-taking-of-raqqa-isis/\#yWVH7_wgHsqp [Diakses 20 April 2018].

Sulaeman, Dina Y. (2013). Prahara Suriah. Jakarta: Pustaka IIMaN.

The Guardian. (2011). Chinese Arms Companies Weapons Gaddafi Regime. [online] Dalam: https://www.theguardian.com/world/2011/sep/05/chinese-armscompanies-weapons-gaddafi-regime. [Diakses 20 April 2018].

UN (United Nations). (2011). Security Council Approves 'No-Fly Zone'over Libya. [online] Dalam: https://www.un.org/press/en/2011/sc10200.doc.htm [Diakses 20 April 2018].

UN (United Nations). (2018). Syria conflict: 2017 deadliest year for children, UN aid official reports. [online] Dalam: https://news.un.org/en/story/2018/03/1004802 [Diakses 5 Mei 2018].

UNODA. (2013). ATT Implementation Toolkit, Module 2: Overview of Obligation. [online] Dalam: https://unoda-web.s3-accelerate.amazonaws.com/wp-content/ uploads/2015/08/2015-08-21-Toolkit-Module-2.pdf [Diakses 5 Mei 2018].

Yakovenko, Alexander. (2016). Russia went to Syria to fight terrorists. We are succeeding. The Guardian, [online]. Dalam: https://www.theguardian.com/ commentisfree/2016/oct/15/syria-russian-ambassador-aleppo-isis [Diakses 12 April 2018]. 